\title{
Scalable Solvo-plasma Production of Porous Tin Oxide Nanowires
}

\author{
Tu Quang Nguyen ${ }^{1,2,3}$, Veerendra Atla ${ }^{1,2}$, Venkat Kalyan Vendra ${ }^{1,2}$, Arjun Kumar Thapa ${ }^{1}$, Jacek \\ B. Jasinski ${ }^{1}$, Thad L. Druffel ${ }^{1}$ and Mahendra K. Sunkara ${ }^{1,2, *}$ \\ ${ }^{1}$ Conn Center for Renewable Energy Research \\ ${ }^{2}$ Department of Chemical Engineering \\ University of Louisville, Louisville, KY 40292 \\ ${ }^{3}$ Advanced Energy Materials, LLC. Louisville, KY 40299 \\ *Email: mahendra@louisville.edu
}

KEYWORDS: tin oxide nanowires, porous nanowires, roll-to-roll, scalable, large quantities, liion batteries

\section{ABSTRACT}

This paper reports a fast, scalable method for synthesizing tin oxide nanowire powder using cheap starting material of commercial tin oxide particles and an atmospheric microwave plasma reactor. Specifically, the synthesis concept involves plasma oxidation of tin oxide powder combined with potassium hydroxide for few seconds to a minute which is orders of magnitude lower than that using hydrothermal or vapor-liquid-solid (VLS) techniques. Even at lab scale, large-scale production of tin oxide nanowire powder as high as 10 grams per hour has been produced. Systematic studies reveal nucleation and growth of $\mathrm{K}_{2} \mathrm{SnO}_{3}$ nanowires from molten alloy involving $\mathrm{KOH}$ and tin oxide. A simple annealing step is used to convert $\mathrm{K}_{2} \mathrm{SnO}_{3}$ intermediate nanowires into pure tin oxide nanowires. The extremely short reaction time of 20 seconds is three orders of magnitude faster than that of traditional hydrothermal method. It was shown that our tin oxide nanowire powder shows a high reversible capacity of $848 \mathrm{mAh} \mathrm{g}^{-1}$ after 
55 cycles at a current density of $100 \mathrm{~mA} \mathrm{~g}^{-1}$. The scalable production technique presented here and the applicability of resulting tin oxide nanowire powders makes it as suitable for practical implementation into lithium-ion battery applications.

\section{Introduction}

Tin oxide nanowires is one of the most promising 1D nanostructures for advanced applications in lithium-ion batteries ${ }^{1}$, solar cells ${ }^{2}$, sensors ${ }^{3}$, optical devices ${ }^{4}$, and electronic devices $^{5}$. However, the wide-spread use of nanowire based materials in to energy device applications has been limited due to the fact that there are no scalable manufacturing methods, yet. For example, the lithium-ion battery electrodes will require production on the order of kilograms even for simple pouch cell prototyping. Thus, the development of reliable, reproducible and simple techniques for production of tin oxide nanowires and their testing into energy devices is of great interest. Up to date, several approaches have been proposed to prepare tin oxide nanowires including chemical vapor deposition ${ }^{6}$, laser ablation ${ }^{7}$, template $\operatorname{method}^{8}$ and most predominantly hydrothermal technique ${ }^{9}$.

Hydrothermal synthesis has been traditionally used to prepare nanostructured materials including nanoparticles and nanowires. However, this approach requires long time scale, high pressure, multiple steps and expensive precursors ${ }^{10}$. Further, in most cases, hydrothermal techniques require the use of surfactant to control the nanowire growth. Also, no clear mechanism for tin oxide nanowires have been proposed. Importantly, the hydrothermal techniques are limited to lab scale (few milligrams to hundred milligrams a batch) ${ }^{11,12}$. Two recent hydrothermal based approaches are microwave assisted hydrothermal and continuous flow hydrothermal method, which can increase the production rate to about $5 \mathrm{~g} /$ day and $10 \mathrm{~g} / \mathrm{hour}$, respectively ${ }^{13,14}$. However, these hydrothermal methods have been shown to work only for nanoparticles (NPs) and not to make nanowires. Another popular method for making nanowire growth is that using vapor-liquid-solid (VLS) process for many semiconductors including tin oxide ${ }^{6}$. However, VLS processes require the use of low pressure, high temperatures, high fabrication cost and $\mathrm{Au}$ as catalyst.

In this work, we report a facile, fast "solvo-plasma" production of tin oxide nanowires using tin oxide particles as a low-cost source. This study demonstrates, for the first time, the 
direct conversion of tin oxide particles to tin oxide nanowires with reaction time scales on the order of a minute or lower. More importantly, various experimental studies are used to understand the underlying principle of nucleation and growth of tin oxide nanowires in the presence of alkali hydroxides. Thin films made using the resulting tin oxide nanowire powders are also investigated for their performance as high capacity anodes in lithium ion batteries.

\section{Experimental}

Tin oxide nanowires are synthesized in an upstream microwave plasma reactor whose details have been described in detail elsewhere ${ }^{15}$. Briefly, tin oxide particles $(1 \div 5 \mu \mathrm{m}$ size, Atlantic Equipment Engineer, Inc) are mixed with $\mathrm{KOH}$ powder in a 3:1 ratio by weight and water is added to make the precursor paste. The precursor paste is then sprinkled on the top of a $1 \mathrm{x} 1$ inch quartz substrate (Figure 1a), which is then carefully exposed to the plasma flame at power of 1.0-1.4 kW, $8 \mathrm{lpm}$ of Air flow for 10 seconds to $5 \mathrm{~min}$. The as-synthesized materials are dispersed in $0.1 \mathrm{M} \mathrm{HCl}$ solution for $1 \mathrm{~h}$ to facilitate ion exchange, washed with deionized water, and annealed by exposure to plasma flame for 1 to $5 \mathrm{~min}$. The samples are characterized using a scanning electron microscope (SEM) (FEI Nova 600), X-ray diffraction (Bruker D8 Discovery with $\mathrm{Cu} \mathrm{K} \alpha$ radiation), and a transmission electron microscope (TEM) (Tecnai F20 FEI TEM operating at $200 \mathrm{kV}$ ).

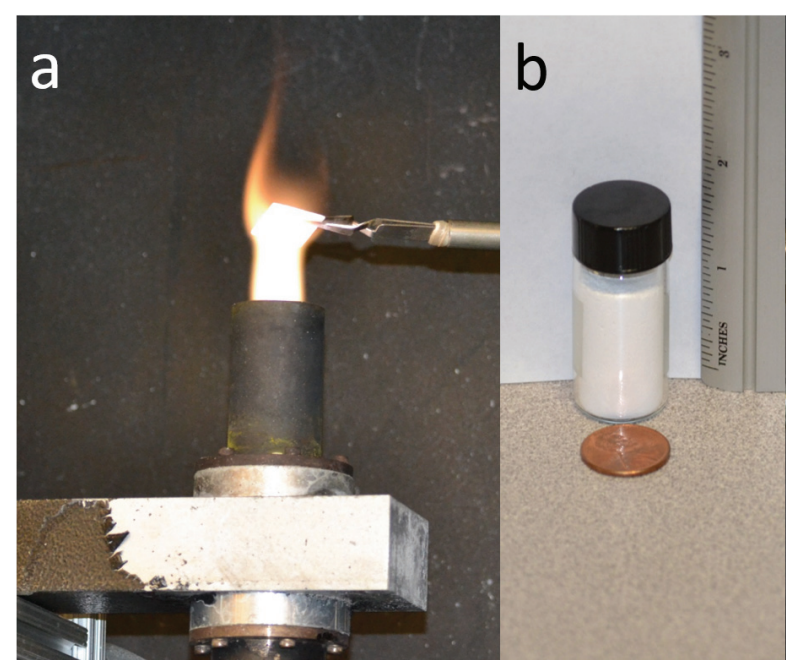

Figure 1. Photograph of an actual experiment: plasma exposure of tin oxide precursor and $\mathrm{KOH}$ paste on quartz substrate a), a bottle of tin oxide nanowire powder of 10 grams produced in one hour reaction time 
The electrochemical measurements are performed using a battery tester (16 Channel Arbin Instruments, USA). The electrode materials were prepared using $70 \mathrm{wt} \%$ active materials with $20 \mathrm{wt} \% \mathrm{AB}$ (acetylene black) and $10 \%$ PVDF binder in NMP. The well-mixed slurry was casted onto a copper foil using a doctor blade. The electrode is dried at $180^{\circ} \mathrm{C}$ for $4 \mathrm{~h}$ under vacuum. The typical loading of active materials is 0.2 to $0.5 \mathrm{mg} / \mathrm{cm}^{2}$. The CR-2032 coin-type assembling is performed in a dry argon-filled glove box. The electrodes are separated by two pieces of glass fiber filter. The electrolyte solution was $1 \mathrm{M} \mathrm{LiPF}_{6}-\mathrm{EC}: \mathrm{DMC}$ (1:2 by volume).

\section{Results and Discussion}

All experiments are performed using inexpensive, commercial tin oxide particles without any further purification by mixing them with $\mathrm{KOH}$ and exposing to atmospheric plasma flame for 15 seconds to 1 minute. Using a 1-inch square substrate, we were able to demonstrate production of tin oxide nanowires at a scale of 10 grams in one hour (Figure 1b). The exposure time used here is less than a minute which is about 3.5 orders of magnitude faster than that using a hydrothermal method. Figure 2a shows SEM images of the resulting tin oxide nanowires that are 2 microns in length and about 50 to $100 \mathrm{~nm}$ in diameter. The TEM images of tin oxide nanowires show highly porous structures of tin oxides, which is due to $\mathrm{HCl}$ ion exchange and plasma annealing step (Figure 2b, c). The BET surface area of the porous tin oxide nanowires turned out to be $37 \mathrm{~m}^{2} / \mathrm{g}$. The BET surface area could be increased further by controlling the ion exchange and annealing parameters. The phase transformation of intermediate nanowires to tin oxide nanowires created the porous structures where potassium and water vapor are removed. The porous structures consisted of interconnected tin oxide nanoparticles. The underlying mechanism for porous structure formation seems to be similar to that suggested in many other reports using hydrothermal synthesis with additional annealing step 9 . However, the actual mechanism is not completely clear in terms of how phase transformation leads to porous nature within the nanowires. Figure $2 \mathrm{c}$ also revealed the twining effect where the boundary in the top left corner clearly showed merging of two nanowires. The merging maybe due to the high

surface diffusion of tin atoms on nanowire surface under plasma exposure ${ }^{16}$. The HR-TEM 
image in Figure $2 \mathrm{~d}$ showed the match of interplanar lattice spacing of $3.35 \AA$ and $2.64 \AA$ for the plane (110) and (101), respectively.

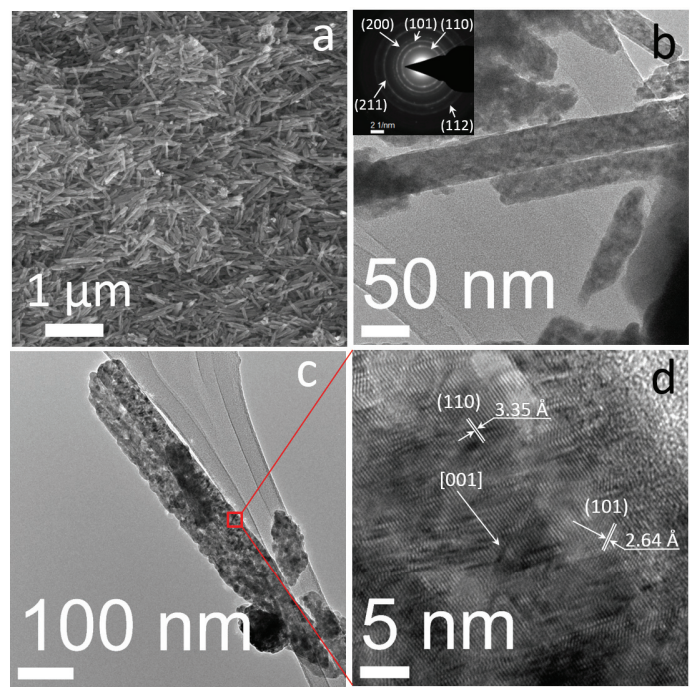

Figure 2. Scanning electron microscopy of tin oxide nanowire powder after annealing a), TEM images b) and c) showing the porous structure and twining effect, (inset) SAED of tin oxide nanowires, HR-TEM image showing the matching interplanar lattice spacing of (110) and (101) plane of tin oxide nanowires d).

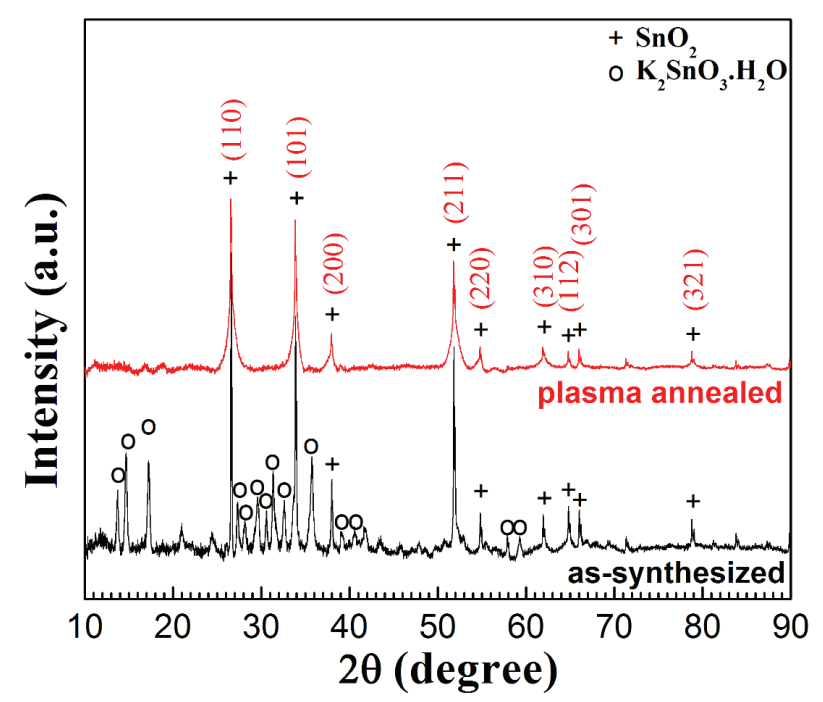

Figure 3. Powder XRD pattern of samples after annealing in plasma showing the pure phase of rutile tin oxide while the as-synthesized samples showing additional intermediate compounds. 


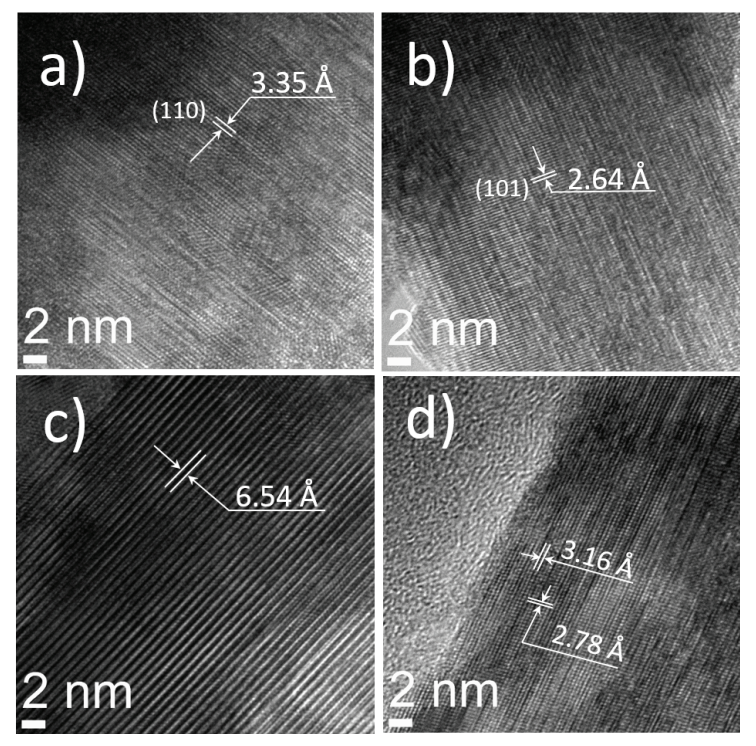

Figure 4. HR-TEM images of as-synthesized samples showing well-matched interplanar lattice spacing of rutile tin oxide in (a) and (b), $\mathrm{K}_{2} \mathrm{SnO}_{3} \cdot \mathrm{H}_{2} \mathrm{O}$ in (c) and (d)

The powder XRD pattern of tin oxide nanowires after annealing in plasma is shown in Figure 3. The diffraction peaks revealed that tin oxide nanowires have tetragonal crystal structure with lattice parameters $\mathrm{a}=\mathrm{b}=4.74 \AA$ and $\mathrm{c}=3.18 \AA$, corresponding bulk rutile tin oxide (PDF00-005-0467). The selected area diffraction pattern also confirms the pure phase tin oxide as in Figure 2b. No other impurity peaks are detected in the tin oxide nanowire samples after annealing in plasma. The Raman spectroscopy of the tin oxide nanowires after annealing shows fundamental peaks at 474, 633, and $775 \mathrm{~cm}^{-1}$ that is well matched with rutile tin oxide ${ }^{17}$ (Figure $\mathrm{S} 1)$. In addition to the peaks of tin oxide phase, the XRD pattern of as-synthesized samples (Figure 3) showed peaks of $\mathrm{K}_{2} \mathrm{SnO}_{3} \cdot \mathrm{H}_{2} \mathrm{O}$ (PDF-00-019-0993). The HR-TEM images showed well-matched interplanar lattice spacing of $\mathrm{SnO}_{2}$ (Figure 4a, b) and layered structure $\mathrm{K}_{2} \mathrm{SnO}_{3} \cdot \mathrm{H}_{2} \mathrm{O}$ (Figure $4 \mathrm{c}, \mathrm{d}$ ). The lattice spacing of $6.54 \AA, 3.16 \AA$ and $2.78 \AA$ correspond to the peaks of $13.5^{\circ}, 28.2^{\circ}$, and $32.2^{\circ}$ of $\mathrm{K}_{2} \mathrm{SnO}_{3} \cdot \mathrm{H}_{2} \mathrm{O}$. EDS analysis shows that the as-synthesized nanowires contain about 13 at.\% of potassium. This confirms that the intermediate compound or as-synthesized compound is $\mathrm{K}_{2} \mathrm{SnO}_{3}$. The hkl index of $\mathrm{K}_{2} \mathrm{SnO}_{3} \cdot \mathrm{H}_{2} \mathrm{O}$ is not available to our knowledge. However, the lattice spacing of tin oxide in Figure $2 \mathrm{~d}$ shows that tin oxide nanowires grown along [001] direction that is in agreement with previous reports ${ }^{10,18}$. [001] direction has highest surface energy that favored the $1 \mathrm{D}$ growth ${ }^{11,19}$. 

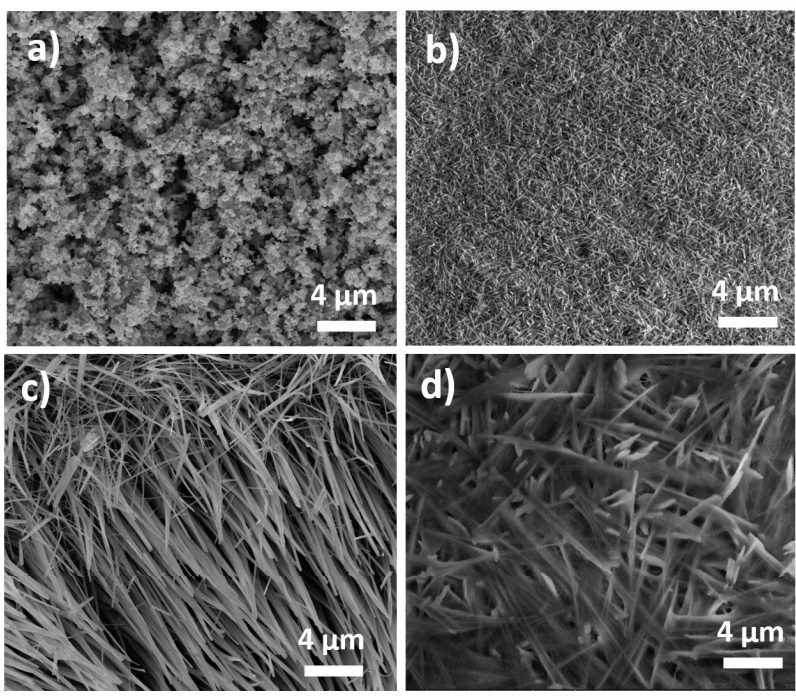

Figure 5. SEM images of (a) tin oxide precursor and as-synthesized $\mathrm{K}_{2} \mathrm{SnO}_{3}$ nanowires at weight ratios of $\mathrm{SnO}_{2}$ to $\mathrm{KOH}$ of (b) 3:1, (c) 1:1, (d) 1:3. Experiments were conducting using plasma flame with power of $1.2 \mathrm{~kW}$ at a duration of 60 seconds

Even though, the above results clearly demonstrate the formation of one-dimensional structures with plasma exposure of tin oxide powder mixed with $\mathrm{KOH}$, there are several questions remain unanswered about the observed 1-D growth. So, experiments were conducted for different weight ratios of $\mathrm{SnO}_{2}$ to $\mathrm{KOH}$ to understand initial stages of growth. Figure 5 showed the SEM images of as-synthesized samples at different weight ratios of $\mathrm{SnO}_{2}$ to $\mathrm{KOH}$ in comparison with the tin oxide particle precursor. Thin, short nanowires of about $70 \mathrm{~nm}$ in diameter and 2 to 4 microns in length are observed at weight ratio of 3 to 1 . When the weight ratio for precursors decreased to 1 to 1 , there is more change in the nanowire diameter and length. As shown in Figure 5c, the resulting nanowires are of 100 to $300 \mathrm{~nm}$ in diameter and 20 to 30 microns in length. The image also shows that nanowires bunch up and seem to be fusing together for samples grown using precursors at a weight ratio of 1 tol. Such sintering of nanowires could be the reason for twining effect seen in Figure 2c. The nanowire diameter increased further when using precursor ratio to 1:3. However, there is the presence of excess $\mathrm{KOH}$ on top of nanowires that make it difficult to quantify diameters. The increase in diameter for resulting nanowires can probably be explained with decreasing supersaturation with decreasing $\mathrm{SnO} 2$ to $\mathrm{KOH}$ ratio from 3:1 to 1:3. 


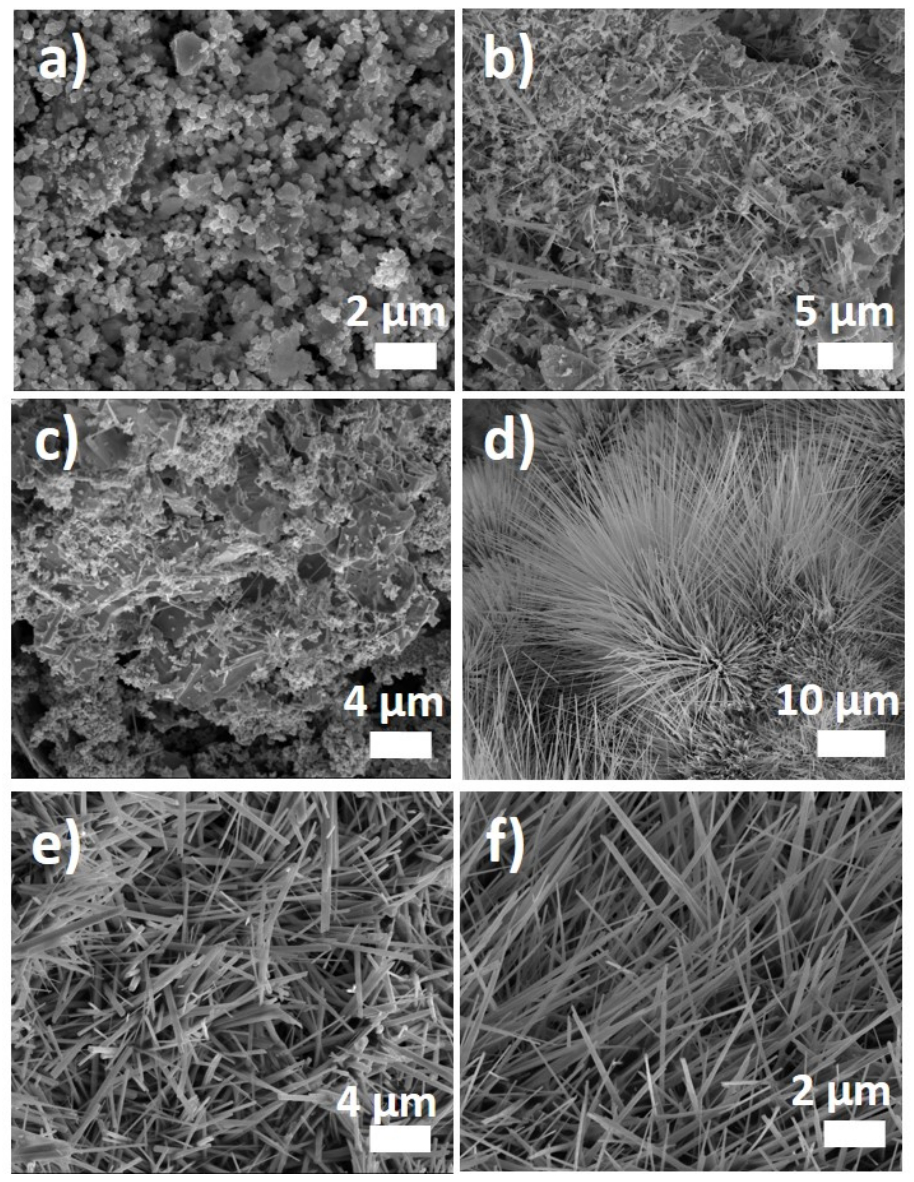

Figure 6. SEM image of as-synthesized sample using a) $\mathrm{SnO}_{2}+\mathrm{KCl}$, b) $\mathrm{Sn}+\mathrm{KOH}$, c) $\mathrm{Sn}+\mathrm{KCl}$, d) $\mathrm{SnO}+\mathrm{KOH}$, e) $\mathrm{K}_{2} \mathrm{SnO}_{3}$, f) $\mathrm{SnO}_{2}+\mathrm{KOH}$. Sample a) to e) prepared using plasma heating for 60 seconds, sample f) prepared using thermal heating at $900^{\circ} \mathrm{C}$ for $2 \mathrm{hrs}$.

Experiments were also performed using different tin precursors such as tin oxide, tin and tin monoxide to determine their impact on reaction time scales and nanowire growth rates. As shown in Figure $6, \mathrm{~K}_{2} \mathrm{SnO}_{3}$ nanowires are obtained using a mixture of tin metal powder or tin mono-oxide particles with $\mathrm{KOH}$. Nanowires obtained using tin metal powder have random diameters and lengths. Nanowires obtained using tin mono-oxide have diameters of about 50 to $100 \mathrm{~nm}$ and lengths up to 50 microns (Figure 6d). In fact, tin oxide nanoparticles are always found together with $\mathrm{K}_{2} \mathrm{SnO}_{3}$ nanowires when tin metal powder used as starting material (Figure $6 \mathrm{~b}, \mathrm{c}$ ). No nanowires formed with either mixture of $\mathrm{H}_{2} \mathrm{O}$ or $\mathrm{KCl}$ with tin oxide particles (Figure 6a). In another experiment, the same mixture of tin oxide particles and $\mathrm{KOH}$ at mass ratio of 3 to 1 is put onto a quartz substrate and was thermally heated to $900^{\circ} \mathrm{C}$ for 2 hours in a box furnace. The similar tin oxide nanowire morphology but longer in length is observed (Figure 6f). 


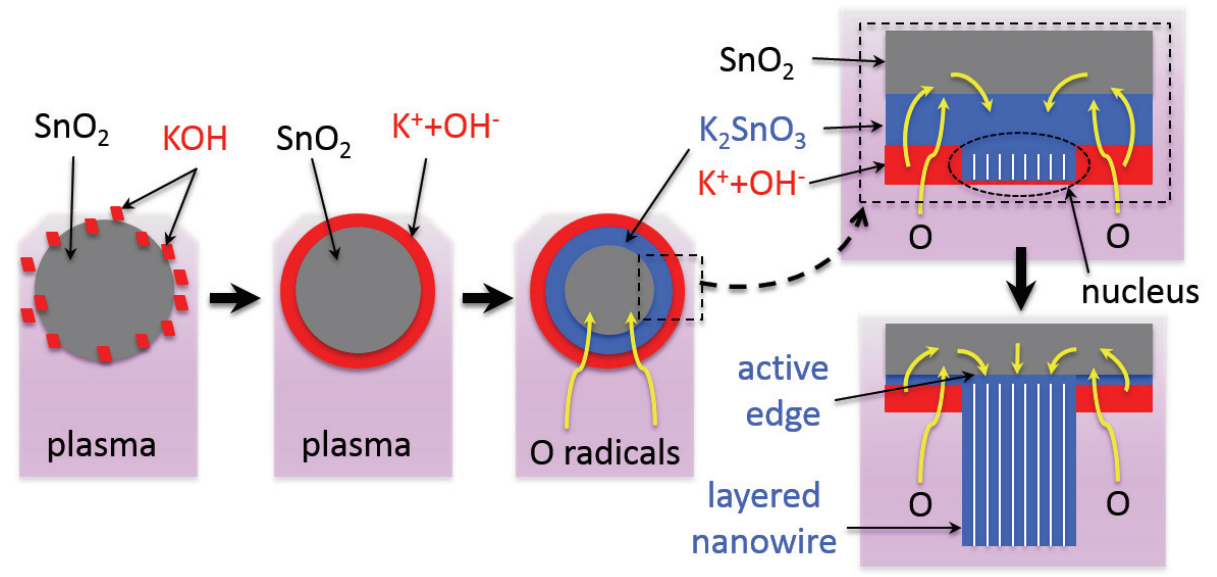

Figure 7. Schematic showing the proposed growth mechanism for growth of tin oxide nanowires. a) Mixture of tin oxide particle and $\mathrm{KOH}$ in plasma flame, b) $\mathrm{KOH}$ got melted into free moving $\mathrm{K}^{+}$and $\mathrm{OH}^{-}$ions, c) diffusion of oxygen radicals, $\mathrm{K}^{+}$and $\mathrm{OH}^{-}$ions into tin oxide particle to form $\mathrm{K}_{2} \mathrm{SnO}_{3}$, d) $\mathrm{K}_{2} \mathrm{SnO}_{3}$ nucleus forming under supersaturation of $\mathrm{K}_{2} \mathrm{SnO}_{3}$, e) layered structure $\mathrm{K}_{2} \mathrm{SnO}_{3}$ grown due to active edge.

Based on all the experimental observations, we propose a mechanism to explain tin oxide nanowire growth in a three step sequence as shown in Figure 7: (1) continuous dissolution of tin oxide particles with $\mathrm{KOH}$ results in supersaturation of tin oxide in molten phase containing $\mathrm{K}$ $\mathrm{Sn}-\mathrm{O}$, (2) phase segregation and bulk nucleation of $\mathrm{K}_{2} \mathrm{SnO}_{3}$ on the surface of tin oxide particles due to non-stable molten phase containing K-Sn-O, (3) $\mathrm{K}_{2} \mathrm{SnO}_{3}$ formation started from surface of tin oxide particles by diffusion-driven self-arrangement and basal attachment ${ }^{20}$. The resulting $\mathrm{K}_{2} \mathrm{SnO}_{3} \mathrm{H}_{2} \mathrm{O}$ phase has layered structure with active sites at the end making it grow faster at ends leading to the one-dimensional growth of layer structured $\mathrm{K}_{2} \mathrm{SnO}_{3}$ nanowires. Extra exposure of $\mathrm{K}_{2} \mathrm{SnO}_{3}$ nanowires also result in tin oxide nanowires. So, the final product can contain pure tin oxide nanowires. But, based on our experimental data, the formation of $\mathrm{K}_{2} \mathrm{SnO}_{3}$ 1-D structures occurs first and then transforms to pure phase tin oxide nanowires. Previous studies using hydrothermal method suggested that the formation of tin oxide nanowires was due to decomposition of intermediate phase of $\mathrm{Na}_{2} \mathrm{Sn}(\mathrm{OH})_{6}$ to tin oxide nuclei followed by condensation to form tin oxide nanowires ${ }^{10,21}$.

In principle, $\mathrm{KOH}$ can easily be melted into free moving $\mathrm{K}^{+}$and $\mathrm{OH}^{-}$ions under plasma exposure or thermal heating up to $406^{\circ} \mathrm{C}$ or higher. Indeed, an in-situ measurement of surface 
temperature using a Pyrometer which showed the temperature to be lower than its minimum detection limit of $475^{\circ} \mathrm{C}$ after 17.4 seconds of exposure time. $\mathrm{KOH}$ probably melted sooner than 10 seconds of exposure time as shown in Figure S2. Free moving $\mathrm{K}^{+}$and $\mathrm{OH}^{-}$ions and oxygen radicals $^{22,23}$ produced by atmospheric plasma flame quickly diffuse into tin oxide structure to form a thin layer of molten melted of $\mathrm{K}_{2} \mathrm{SnO}_{3}$ on the surface of tin oxide particles.
$\mathrm{SnO}_{2}+2 \mathrm{~K}^{+}+2 \mathrm{OH}^{-}+\mathrm{O} \rightarrow \mathrm{K}_{2} \mathrm{SnO}_{3}+\mathrm{H}_{2} \mathrm{O}+1 / 2 \mathrm{O}_{2}$
(1) $\mathrm{G}_{1,900}$

Fast diffusion of $\mathrm{K}^{+}, \mathrm{OH}^{-}$ions and oxygen radicals into tin oxide particles make tin oxide quickly dissolved to form a molten phase containing $\mathrm{K}$, Sn and $\mathrm{O}$ in which the $\mathrm{K}_{2} \mathrm{SnO}_{3}$ phase forms and nucleates out. $\mathrm{K}_{2} \mathrm{SnO}_{3}$ is a layered structure itself in which the growth predominantly happens at its ends (at edge sites). The growth direction along the wide d-spacing of $6.54 \AA$ was confirmed in all of the TEM analysis of the as-synthesized samples. Availability of $\mathrm{K}^{+}$and $\mathrm{OH}^{-}$ ions make the edge, where nucleus is in contact with molten $\mathrm{K}_{2} \mathrm{SnO}_{3}$, is the only active edge that nucleus can propagate to form nanowire.

$\mathrm{SnO}_{2}+2 \mathrm{~K}^{+}+2 \mathrm{OH}^{-} \rightarrow \mathrm{K}_{2} \mathrm{SnO}_{3}+\mathrm{H}_{2} \mathrm{O}$

Under thermal heating, the reaction (1) can be revised as shown in reaction (2). Under thermal heating up to $900^{\circ} \mathrm{C}, \mathrm{KOH}$ also became molten into free moving $\mathrm{K}^{+}$and $\mathrm{OH}^{-}$ions. The same growth mechanism can be applied in case of thermal heating. Gibbs free energy of $\mathrm{K}_{2} \mathrm{SnO}_{3}$ is not available yet. However, by assuming that the Gibbs free energy of $\mathrm{K}_{2} \mathrm{SnO}_{3}$ is a specific value of $\mathrm{X}_{\mathrm{KSO}}$, then we could calculate Gibbs free energy change of above reactions at $900^{\circ} \mathrm{C}$. $\mathrm{G}_{1,900}$ and $\mathrm{G}_{2,900}$ are of $\mathrm{X}_{\mathrm{KSO}}+256.45$ and $\mathrm{X}_{\mathrm{KSO}}+432.84 \mathrm{~kJ}$. The difference of $176.39 \mathrm{~kJ}$ in Gibbs free energy indicates that presence of plasma makes the reaction (1) more spontaneous than reaction (2). Indeed, fast nanowire growth rate of $1 \mathrm{~m} / \mathrm{min}$ is observed with plasma heating while thermal heating resulted in slow nanowire growth rate of $0.04 \mathrm{~m} / \mathrm{min}$. As a main specie of atmospheric plasma, highly active oxygen radicals ${ }^{23}$ with $\mathrm{K}^{+}, \mathrm{OH}^{-}$ions diffuse quickly into tin oxide structure to form $\mathrm{K}_{2} \mathrm{SnO}_{3}$. Fast diffusion of oxygen radicals, $\mathrm{K}^{+}$, and $\mathrm{OH}^{-}$ions results in fast growth rate of nanowires in plasma heating.
$\mathrm{SnO}+2 \mathrm{~K}^{+}+2 \mathrm{OH}^{-}+\mathrm{O} \rightarrow \mathrm{K}_{2} \mathrm{SnO}_{3}+\mathrm{H}_{2} \mathrm{O}$
(3) $\mathrm{G}_{3,900}$ 
In another experiment, tin mono-oxide is used as starting material. The reaction occurs as reaction (3). The Gibbs free energy $\left(\mathrm{G}_{3,900}\right)$ is calculated to be $\mathrm{X}_{\mathrm{KsO}}+87.75 \mathrm{~kJ}$ which is 168.70 $\mathrm{kJ}$ lower than that of reaction (1) where tin oxide is used. As expected, the use of tin mono-oxide has increased the nanowire growth rate up to $40 \mathrm{~m} / \mathrm{min}$ that is 40 times faster than the use of tin oxide with plasma heating and 1000 time faster than the use of tin oxide with thermal heating.

$\mathrm{Sn}+2 \mathrm{~K}^{+}+2 \mathrm{OH}^{-}+2 \mathrm{O} \rightarrow \mathrm{K}_{2} \mathrm{SnO}_{3}+\mathrm{H}_{2} \mathrm{O}$

The use of tin metal as starting material made a big difference. Tin metal can react directly with $\mathrm{KOH}$ to form $\mathrm{K}_{2} \mathrm{SnO}_{3}$ nanowires as reaction (4). Tin metal can also get oxidized to tin mono oxides, tin oxides and then these oxides react with $\mathrm{KOH}$ to form $\mathrm{K}_{2} \mathrm{SnO}_{3}$ nanowires. Therefore, random nanowire lengths are observed as tin mono-oxides tend to form long nanowire while tin oxides produce short nanowires. Several resulting tin mono-oxide or tin oxide particles, did not get in contact with $\mathrm{KOH}$ and are observed as particles in any experiments using tin metal as starting material.

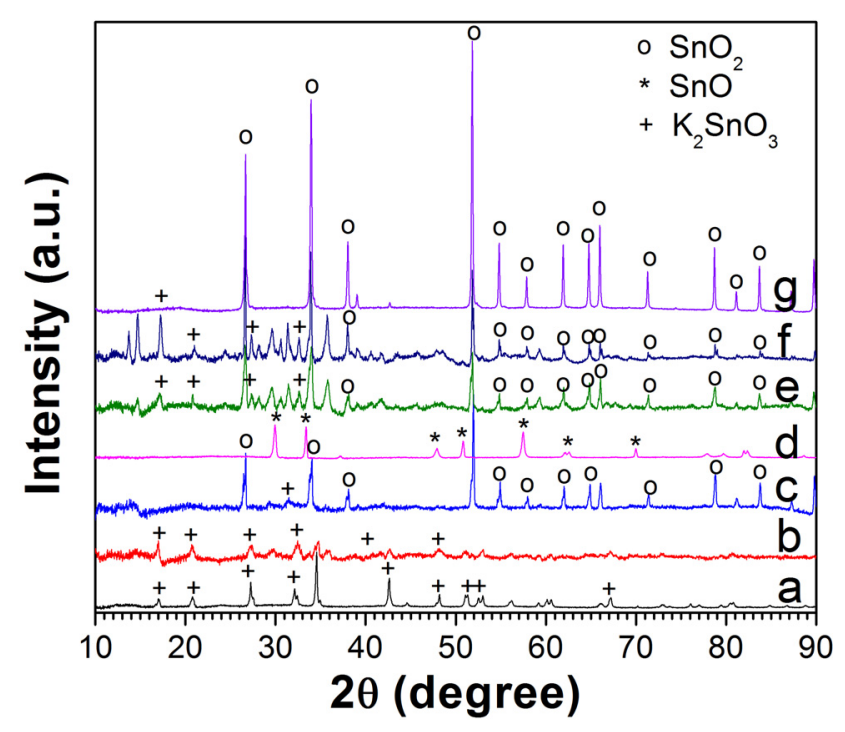

Figure 8. XRD pattern of a) $\mathrm{K}_{2} \mathrm{SnO}_{3}$ particle precursor, b) as-synthesized nanowires using $\mathrm{K}_{2} \mathrm{SnO}_{3}$ particles, c) as-synthesized nanowires using tin mono oxide particles, d) tin mono oxide particle precursor, e) as-synthesized nanowires using tin oxide particles for 10 seconds exposure 
time, f) as-synthesized nanowires using tin oxide particles for 60 seconds exposure time, g) $\mathrm{SnO}_{2}$ particle precursor

The structure of as-synthesized nanowires using different starting materials for tin is investigated to understand the transformation of tin-based particle precursor to $\mathrm{K}_{2} \mathrm{SnO}_{3}$ nanowires. Figure 8 shows the XRD pattern of as-synthesized nanowire samples using tin oxide, tin mono-oxide and $\mathrm{K}_{2} \mathrm{SnO}_{3}$ particles. Clearly, the nanowires prepared using $\mathrm{K}_{2} \mathrm{SnO}_{3}$ particles exhibit the same peaks of $\mathrm{K}_{2} \mathrm{SnO}_{3}$ phase as shown in Figure 8a and 8b. Peaks of $\mathrm{K}_{2} \mathrm{SnO}_{3}$ appear in the samples prepared using tin oxide particles after 10 seconds of exposure time (see Figure 8e). As the exposure time increased to 60 seconds, the intensity of these peaks increase significantly as shown in Figure 8f. In other experiment with $\mathrm{K}_{2} \mathrm{SnO}_{3}$ particles as precursor, $\mathrm{K}_{2} \mathrm{SnO}_{3}$ remains the same phase but the morphology changes from particle form to nanowire form (Figure 8a, b and Figure 6e). The formation $\mathrm{K}_{2} \mathrm{SnO}_{3}$ nanowires using $\mathrm{K}_{2} \mathrm{SnO}_{3}$ particles will be investigated for more detail in another study. The use of tin mono oxide as precursor does not show the formation of $\mathrm{K}_{2} \mathrm{SnO}_{3}$. As shown in Figure 6d, the long nanowires prepared using tin mono oxide probably experience high temperature gradient and transform directly to tin oxide phase under plasma exposure. This is advantageous as it can further increase the production capacity of tin oxide nanowires using a roll-to-roll setup and expected to introduce a new commercial production of tin oxide nanowire powder for practical applications such as lithium ion batteries, solar cells. As shown in Figure 9, the production capacity can be controlled by the thickness of precursor film, width of belt, speed of belt and plasma power. In our setup, the belt width of 2 inches, the plasma power of 0.8 to $2.5 \mathrm{~kW}$, belt speed of 1 to 2 inches per minutes for exposure time of 30 seconds to 1 minute, the precursor film thickness $100 \mathrm{~m}$ to $1 \mathrm{~mm}$. A simple calculation for plasma power of $1.5 \mathrm{~kW}$, belt speed of 1 inch per minute, results in a production rate of 31 to 310 grams/hour for precursor thickness of $100 \mathrm{~m}$ to $1 \mathrm{~mm}$ using estimated density of dried precursor film of $4 \mathrm{~g} / \mathrm{cm}^{3}$. 

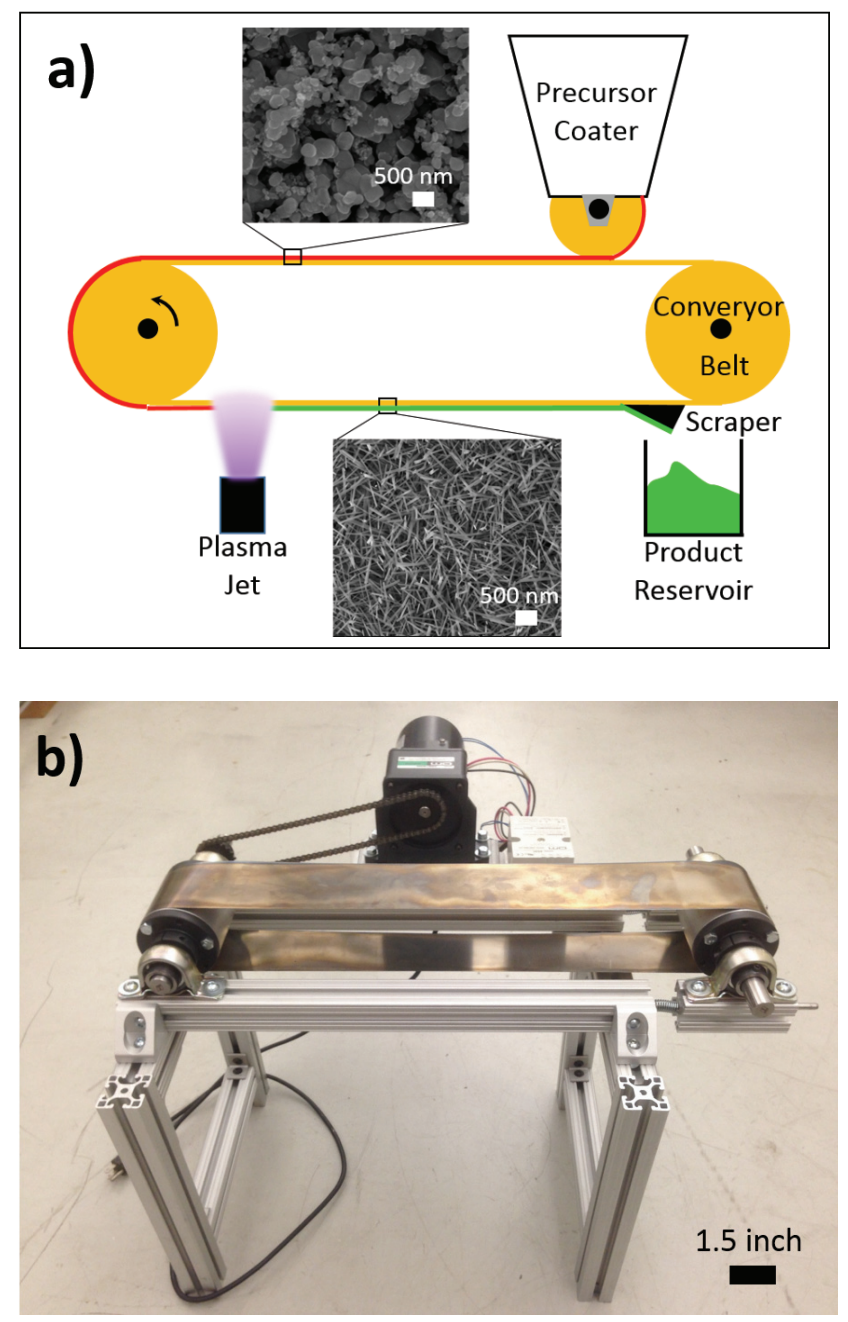

Figure 9. a) Roll-to-roll setup for commercial production of tin oxide nanowire powder; b) A photo of lab-scale conveyor belt

Availability of porous tin oxide nanowires in large quantities should be very interesting for prototyping applications in batteries, gas sensors and catalysts ${ }^{24}$. For lithium ion battery application, tin and its oxides are one of the most important anode materials due to their highest volumetric capacity and decent gravimetric capacity of $7.25 \mathrm{Ah} \mathrm{cm}^{-3}$ and $994 \mathrm{mAh} \mathrm{g}^{-1}$ for tin, $5.47 \mathrm{Ah} \mathrm{cm}^{-3}$ and $781 \mathrm{mAh} \mathrm{g}^{-1}$ for tin oxide, respectively ${ }^{25,26}$. Moreover, nanowire structures are also known to provide fast charge transport and stress accommodation for lithium ion batteries. In spite of these advantages, tin oxide has been shown to suffer from two major challenges. In addition to mechanical degradation due to volume change (about $250 \%)^{27}$, tin oxide also suffers from chemical degradation, i.e., pulverization of tin oxide into tin and non-conducting $\mathrm{Li}_{2} \mathrm{O}$ phase. Typically, tin and tin oxide based materials suffer from large irreversible capacity loss in 
first few cycles and continue to fade in capacity with cycling. Recently, Meduri et al. reported that tin nanocluster on tin oxide nanowires could accommodate the volume expansion and increase the conductivity which is resulted in high reversible capacity of $814 \mathrm{mAh} \mathrm{g}^{-1}$ after 100 cycles $^{1}$. Based on this concept, the resulting nanowire powders from our synthesis have been treated and tested in lithium ion battery anodes.
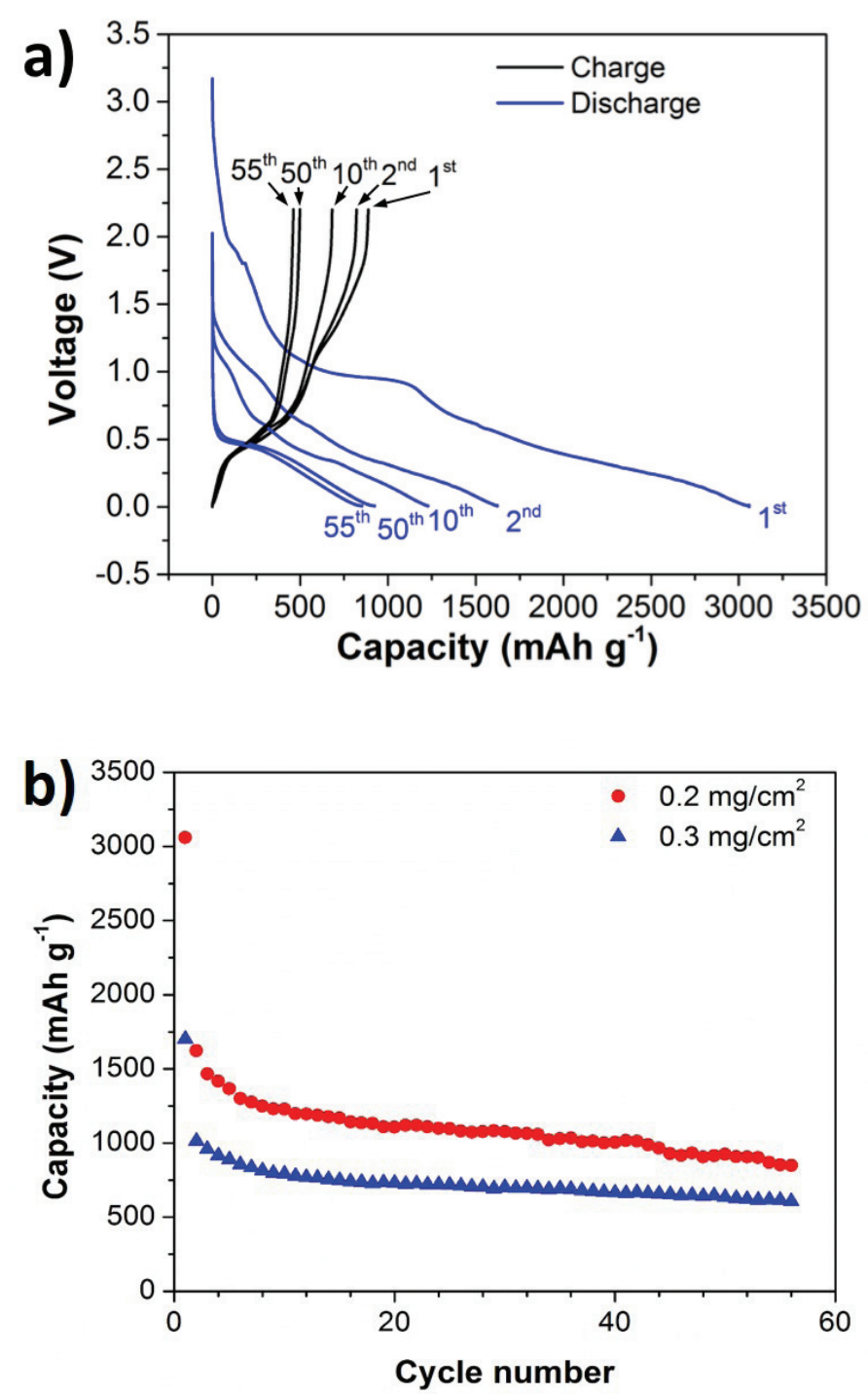

Figure 10. Galvanostatic curves a) and discharge capacity vs. cycle number b) of tin nanoclusters covered tin oxide nanowires at current density of $100 \mathrm{~mA} / \mathrm{g}$

The resulting tin oxide nanowire powders from our plasma oxidation technique are partially reduced in a hydrogen microwave plasma reactor to form tin nanocluster on the surface 
of tin oxide nanowires. The tin nanocluster covered tin oxide nanowires are used as active materials for battery testing. To confirm the durability of the tin oxide nanowire electrodes, all of the electrodes are charged and discharged in the voltage range of $0.005-2.2 \mathrm{~V}$ at a current density of $100 \mathrm{~mA} / \mathrm{g}$ (Figure 10). The high initial capacity of $1700 \mathrm{mAh} \mathrm{g}^{-1}$ is due to the decomposition of electrolyte to form solid electrolyte layer, the reduction of tin oxide to tin, and the insertion of $\mathrm{Li}$ ion into tin oxide and tin to form $\mathrm{Li}_{4.4} \mathrm{Sn}$ alloy. The capacity decreases in first few cycles and remained stable at $614 \mathrm{mAh} \mathrm{g}^{-1}$ after 55 cycles. Another set of experiments with lower loading of $0.2 \mathrm{mg} / \mathrm{cm}^{2}$ shows exceptional high initial capacity of $3059 \mathrm{mAh} \mathrm{g}^{-1}$. The capacity drops quickly in the second cycle to $1623 \mathrm{mAh} \mathrm{g}^{-1}$ and remains stable at $848 \mathrm{mAh} \mathrm{g}^{-1}$ after 55 cycles at the same current density of $100 \mathrm{~mA} / \mathrm{g}$. This is one of the highest capacity retentions obtained for tin oxide. We believe that this high capacity is derived from (1) porous structure of tin oxide which provide high electrode-electrolyte contact area to accommodate the volume change during cycling and to provide pathways for fast transportation of lithium ions and easy accessibility of electrolytes $^{28}$; (2) lower loading leading to minimum delamination which has been reported as a major issue with tin oxide nanowires ${ }^{29}$.

\section{Conclusions}

In summary, a simple concept for fast, scalable method is presented and studied for converting tin oxide particles to tin oxide nanowires by mixing it with potassium hydroxide and exposing to an atmospheric microwave plasma reactor. The reaction time scales have been found to be on the order of few tens of seconds to a minute which makes this technique highly scalable. A production capacity of 300 grams per hour can be obtained by a simple lab-scale roll-to-roll setup. A systematic set of experiments revealed the presence of intermediate phase $\left(\mathrm{K}_{2} \mathrm{SnO}_{3} \cdot \mathrm{H}_{2} \mathrm{O}\right)$ formation which could be held responsible for the observed one-dimensional growth. Further acid wash and annealing of $\mathrm{K}_{2} \mathrm{SnO}_{3} \cdot \mathrm{H}_{2} \mathrm{O}$ allowed for formation of porous tin oxide nanowires. The resulting porous tin oxide nanowires showed a high reversible capacity of $848 \mathrm{mAh} \mathrm{g}^{-1}$ after 55 cycles at a current density of $100 \mathrm{~mA} / \mathrm{g}$.

\section{ASSOCIATED CONTENT}


Supporting Information: Raman spectrum of porous tin oxide nanowires, In-situ measurement of sample surface temperature, Thermodynamic data and growth rate calculations.

\section{AUTHOR INFORMATION}

Corresponding Author: mahendra@louisville.edu

\section{ACKNOWLEDGMENT}

Authors gratefully acknowledge the Conn Center for Renewable Energy Research for facilities and access to characterization equipment. This material is based upon work supported by the National Science Foundation under Cooperative Agreement No. 1355438.

\section{REFERENCES}

(1) Meduri, P.; Pendyala, C.; Kumar, V.; Sumanasekera, G. U.; Sunkara, M. K., Hybrid Tin Oxide Nanowires as Stable and High Capacity Anodes for Li-Ion Batteries. Nano Letters 2009, 9, (2), 612-616.

(2) Gubbala, S.; Russell, H. B.; Shah, H.; Deb, B.; Jasinski, J.; Rypkema, H.; Sunkara, M. K., Surface properties of $\mathrm{SnO} 2$ nanowires for enhanced performance with dye-sensitized solar cells. Energy \& Environmental Science 2009, 2, (12), 1302-1309.

(3) Hui, H.; Tan, O. K.; Lee, Y. C.; Tse, M. S.; Guo, J.; White, T., Effects of plasma treatment on the growth of SnO 2 nanorods from SnO 2 thin films. Nanotechnology 2006, 17, (3), 743.

(4) Chandra, D.; Mukherjee, N.; Mondal, A.; Bhaumik, A., Design and Synthesis of Nanostructured Porous SnO2 with High Surface Areas and Their Optical and Dielectric Properties. The Journal of Physical Chemistry C 2008, 112, (23), 8668-8674.

(5) Kolmakov, A.; Potluri, S.; Barinov, A.; Menteş, T. O.; Gregoratti, L.; Niño, M. A.; Locatelli, A.; Kiskinova, M., Spectromicroscopy for Addressing the Surface and Electron Transport Properties of Individual 1-D Nanostructures and Their Networks. ACS Nano 2008, 2, (10), 1993-2000.

(6) Dai, Z. R.; Gole, J. L.; Stout, J. D.; Wang, Z. L., Tin Oxide Nanowires, Nanoribbons, and Nanotubes. The Journal of Physical Chemistry B 2002, 106, (6), 1274-1279.

(7) Liu, Z.; Zhang, D.; Han, S.; Li, C.; Tang, T.; Jin, W.; Liu, X.; Lei, B.; Zhou, C., Laser Ablation Synthesis and Electron Transport Studies of Tin Oxide Nanowires. Advanced Materials 2003, 15, (20), 1754-1757.

(8) Zhang, H.; Tan, Z.; Xu, P.; Oh, K.; Wu, R.; Shi, W.; Jiao, Z., Preparation of SnO<sub $>2</$ sub $>$ Nanowires by Solvent-Free Method Using Mesoporous Silica Template and Their Gas Sensitive Properties. Journal of Nanoscience and Nanotechnology 2011, 11, (12), 11114-11118.

(9) Wang, Y.; Jiang, X.; Xia, Y., A Solution-Phase, Precursor Route to Polycrystalline SnO2 Nanowires That Can Be Used for Gas Sensing under Ambient Conditions. Journal of the American Chemical Society 2003, 125, (52), 16176-16177.

(10) Zhang, D.-F.; Sun, L.-D.; Xu, G.; Yan, C.-H., Size-controllable one-dimensinal SnO2 nanocrystals: synthesis, growth mechanism, and gas sensing property. Physical Chemistry Chemical Physics 2006, 8, (42), 4874-4880. 
(11) Cheng, B.; Russell, J. M.; Shi; Zhang, L.; Samulski, E. T., Large-Scale, Solution-Phase Growth of Single-Crystalline SnO2 Nanorods. Journal of the American Chemical Society 2004, 126, (19), 5972-5973.

(12) Jian, J. K.; Chen, X. L.; Wang, W. J.; Dai, L.; Xu, Y. P., Growth and morphologies of large-scale SnO2 nanowires, nanobelts and nanodendrites. Appl Phys A 2003, 76, (2), 291-294.

(13) Cabanas, A.; Darr, J. A.; Lester, E.; Poliakoff, M., A continuous and clean one-step synthesis of nano-particulate CeZrO solid solutions in near-critical water. Chemical Communications 2000, (11), 901902.

(14) Chung, C.-C.; Chung, T.-W.; Yang, T. C. K., Rapid Synthesis of Titania Nanowires by MicrowaveAssisted Hydrothermal Treatments. Industrial \& Engineering Chemistry Research 2008, 47, (7), 23012307.

(15) Kumar, V.; Kim, J. H.; Jasinski, J. B.; Clark, E. L.; Sunkara, M. K., Alkali-Assisted, Atmospheric Plasma Production of Titania Nanowire Powders and Arrays. Crystal Growth \& Design 2011, 11, (7), 2913-2919.

(16) Ostrikov, K.; Levchenko, I.; Cvelbar, U.; Sunkara, M.; Mozetic, M., From nucleation to nanowires: a single-step process in reactive plasmas. Nanoscale 2010, 2, (10), 2012-2027.

(17) Zhou, J. X.; Zhang, M. S.; Hong, J. M.; Yin, Z., Raman spectroscopic and photoluminescence study of single-crystalline SnO2 nanowires. Solid State Communications 2006, 138, (5), 242-246.

(18) Wang, Y.; Lee, J. Y.; Deivaraj, T. C., Controlled Synthesis of V-shaped SnO2 Nanorods. The Journal of Physical Chemistry B 2004, 108, (36), 13589-13593.

(19) Beltrán, A.; Andrés, J.; Longo, E.; Leite, E. R., Thermodynamic argument about SnO2 nanoribbon growth. Applied Physics Letters 2003, 83, (4), 635-637.

(20) Ostrikov, K.; Neyts, E. C.; Meyyappan, M., Plasma nanoscience: from nano-solids in plasmas to nano-plasmas in solids. Advances in Physics 2013, 62, (2), 113-224.

(21) Qin, L.; Xu, J.; Dong, X.; Pan, Q.; Cheng, Z.; Xiang, Q.; Li, F., The template-free synthesis of square-shaped SnO 2 nanowires: the temperature effect and acetone gas sensors. Nanotechnology 2008, 19, (18), 185705.

(22) Davide, M.; Sankaran, M., Microplasmas for nanomaterials synthesis. Journal of Physics D: Applied Physics 2010, 43, (32), 323001.

(23) Mozetič, M.; Cvelbar, U.; Sunkara, M. K.; Vaddiraju, S., A Method for the Rapid Synthesis of Large Quantities of Metal Oxide Nanowires at Low Temperatures. Advanced Materials 2005, 17, (17), 2138-2142.

(24) Martinez, C. J.; Hockey, B.; Montgomery, C. B.; Semancik, S., Porous Tin Oxide Nanostructured Microspheres for Sensor Applications. Langmuir 2005, 21, (17), 7937-7944.

(25) Derrien, G.; Hassoun, J.; Panero, S.; Scrosati, B., Nanostructured Sn-C Composite as an Advanced Anode Material in High-Performance Lithium-Ion Batteries. Advanced Materials 2007, 19, (17), 23362340.

(26) Winter, M.; Besenhard, J. O., Electrochemical lithiation of tin and tin-based intermetallics and composites. Electrochimica Acta 1999, 45, (1-2), 31-50.

(27) Wachtler, M.; Winter, M.; Besenhard, J. O., Anodic materials for rechargeable Li-batteries. Journal of Power Sources 2002, 105, (2), 151-160.

(28) Mei, L.; Li, C.; Qu, B.; Zhang, M.; Xu, C.; Lei, D.; Chen, Y.; Xu, Z.; Chen, L.; Li, Q.; Wang, T., Small quantities of cobalt deposited on tin oxide as anode material to improve performance of lithium-ion batteries. Nanoscale 2012, 4, (18), 5731-5737.

(29) Nguyen, T. Q.; Thapa, A. K.; Vendra, V. K.; Jasinski, J. B.; Sumanasekera, G. U.; Sunkara, M. K., High rate capacity retention of binder-free, tin oxide nanowire arrays using thin titania and alumina coatings. RSC Advances 2014, 4, (7), 3312-3317. 
TOC

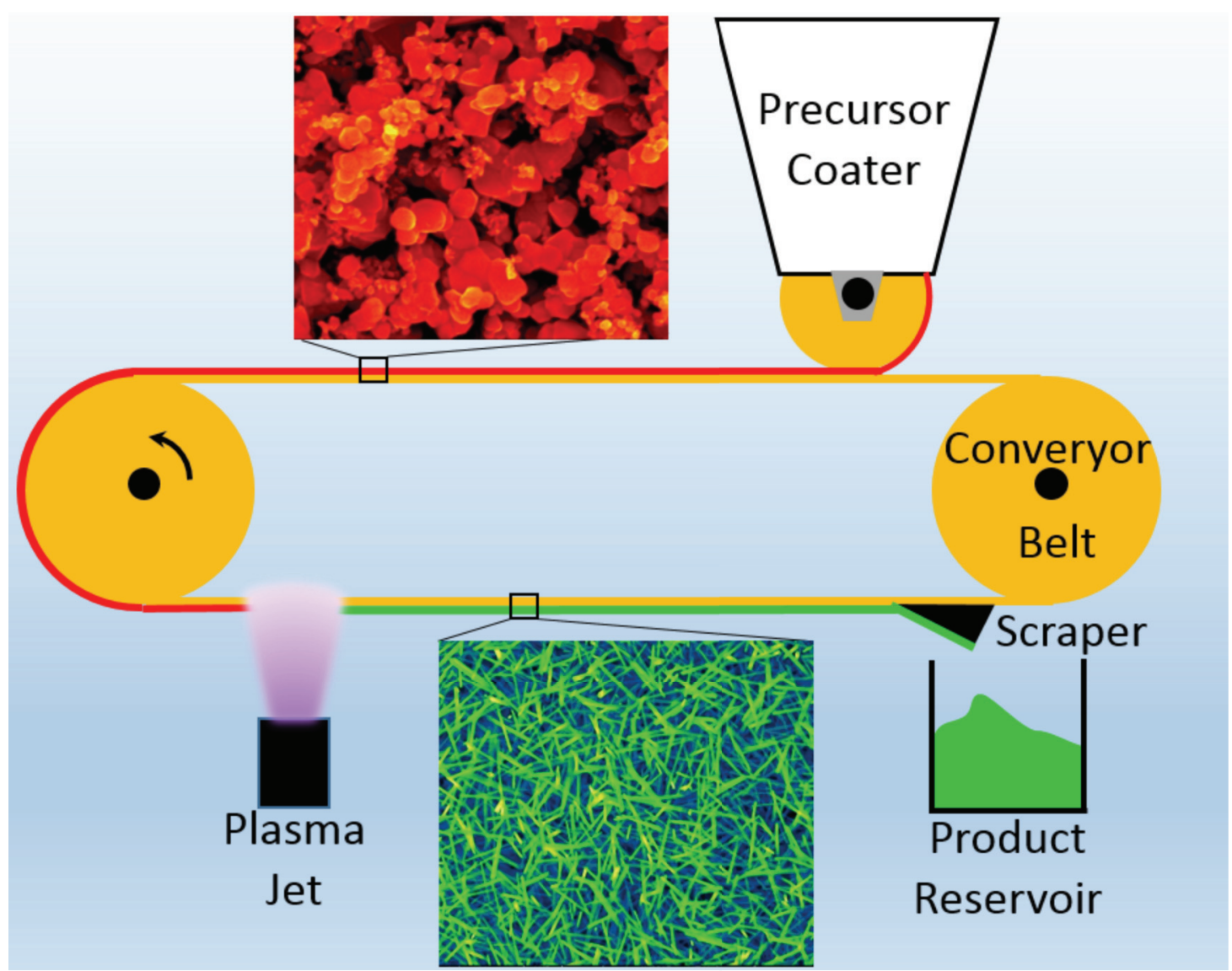

